\title{
Postpartum angiopathy with reversible cerebral vasoconstriction syndrome (RCVS) Imaging in diagnosis and follow-up
}

Ligia Lima Bittencourt, Antonio Carlos Martins Maia Júnior, Antônio José da Rocha

A 27-year-old previously healthy woman, nulliparae, was admitted with an acute onset of severe occipital headache, 10 days after an elective cesarean. Her medical history and laboratory were unremarkable. Postdural puncture headache was dismissed. Progressive worsening of the pain was followed by amaurosis and numbness. The diagnosis of postpartum angiopathy with RCVS was established on clinical and imaging basis (Fig 1). A brief course of glucocorticoids was instituted. She had a fully recovery without any sequelae. MR followup showed the reversibility of the imaging abnormalities with only a slight residual parietal gliosis (Fig 2 and 3). Differential diagnosis with eclampsia was excluded on clinical basis. Postpartum angiopathy has been considered as a prototype of RCVS characterized by abrupt onset of thunderclap headache associated with reversible segmental narrowing of cerebral arteries ${ }^{1,2}$. MR should be performed in such clinical setting to support the diagnosis and follow-up ${ }^{3}$.

\section{REFERENCES}

1. Singhal $A B$. Postpartum angiopathy with reversible posterior leukoencephalopathy. Arch Neurol 2004; 61:411-416.

2. Ducros A, Boukobza M, Porcher R, Sarov M, Valade D, Bousser M-G. The clinical and radiological spectrum of reversible cerebral vasoconstriction syndrome: a prospective series of 67 patients. Brain 2007;130:3091-3101.

3. Calabrese LH, Dodick DW, Schwedt TJ, Singhal AB. Narrative review: reversible cerebral vasoconstriction syndromes. Ann Intern Med 2007;146:34-44.

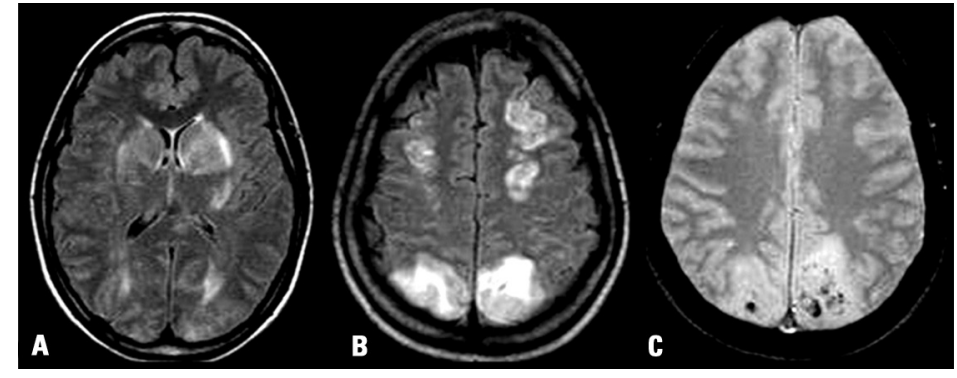

Fig 1. Initial FLAIR images [A-B] depicted multiple cortical and subcortical hyperintensities consistent with vasogenic edema, confirmed on DWI (not shown). $2^{*}[\mathrm{C}]$ showed focal hemorrhages in subcortical parietal lobes.

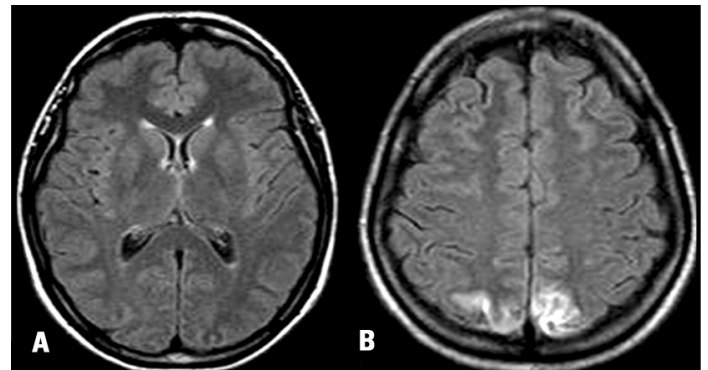

Fig 2. Follow-up MRI (two months later). FLAIR images [A-B] only exhibited a small area of sequelar gliosis in parietal lobes.

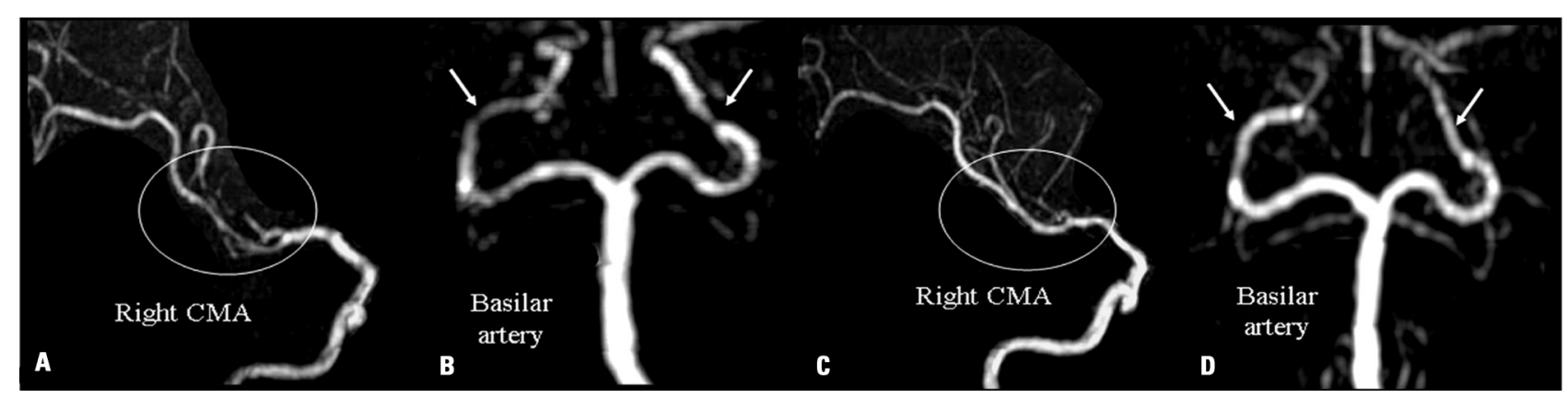

Fig 3. MR angiography confirmed multiple segmental narrowing of the cerebral arteries [A and B] compatible with RCVS. Comparative MRA during the follow-up [C and D] demonstrated resolution of cerebral arterial vasoconstriction.

ANGIOPATIA PUERPERAL COM SÍNDROME DE VASOCONSTRICÇÃO CEREBRAL REVERSíVEL (SVCR): ACHADOS DE IMAGEM E FOLLOW UP Section of Neuroradiology, Santa Casa de Misericórdia de São Paulo, São Paulo SP, Brazil.

Correspondence: Ligia L. Bittencourt - Rua Dr Martinico Prado 71 - 01224-010 São Paulo SP - Brasil. E-mail: ligiabittencourt@yahoo.com.br Received 22 November 2010. Received in final form 21 December 2010. Accepted 28 December 2010. 